The final publication is available at Wiley via

http://onlinelibrary.wiley.com/doi/10.1002/cpp.2125/full 


\title{
Developments on committed action: Validity of the CAQ-8 and analysis of committed action's role in depressive symptomatology in breast cancer patients and healthy individuals
}

\author{
Inês A. Trindade, MSc, PhD student ${ }^{1}$ * \\ Joana Marta-Simões, MSc ${ }^{1}$ \\ Cláudia Ferreira, $\mathrm{PhD}^{1}$ \\ José Pinto-Gouveia, $\mathrm{MD}, \mathrm{PhD}^{1}$
}
${ }^{1}$ CINEICC - Cognitive and Behavioural Centre for Research and Intervention Faculty of Psychology and Educational Sciences University of Coimbra, Portugal

* Correspondence concerning this article should be addressed to:

Inês A. Trindade

Email: almeidatrindade@fpce.uc.pt

CINEICC, Faculdade de Psicologia e Ciências da Educação,

Universidade de Coimbra

Rua do Colégio Novo, Apartado 6153

3001-802 Coimbra, Portugal

Telephone: (+351) 239851450

Fax: (+351) 239851462 


\title{
Developments on committed action: Validity of the CAQ-8 and analysis of committed action's role in depressive symptomatology in breast cancer patients and healthy individuals
}

\begin{abstract}
Committed action, a process of acceptance and commitment therapy's psychological flexibility model, is considered an understudied construct that currently can only be measured by one instrument, the Committed Action Questionnaire (CAQ8). This study aims at analysing the psychometric properties of the CAQ-8 in healthy individuals and breast cancer patients. This study also aims to explore the specific meditational role of committed action in the well-established relationship between experiential avoidance and depression symptoms.
\end{abstract}

The healthy sample comprised 294 adults from the general population, and the breast cancer samples comprised 82 participants. Both groups completed the validated self-report measures. CAQ-8's robustness was examined through validity analyses, confirmatory factor analyses, and multigroup analysis. The meditational model was conducted using structural equation modelling.

The CAQ-8 presented good internal consistency and construct, convergent, concurrent, and divergent validity in both samples. Further, the CAQ-8 showed incremental validity over a measure of engaged living. Findings also demonstrated measurement invariance between healthy individuals and breast cancer patients. Regarding the conducted meditational model that was also invariant between the two analysed groups, it was demonstrated that part of the effect that experiential avoidance holds on depressive symptomatology is explained by committed action. 
This study suggests that the CAQ-8 is adequate for use in healthy and cancer populations. Moreover, it provides novel, empirical support regarding the links between committed action, experiential avoidance, and depressed mood, being also the first investigation to particularly study committed action in a cancer population. Implications for theory and practice are discussed.

Keywords: committed action; depression symptoms; acceptance and commitment therapy; confirmatory factor analysis; multi-group analysis. 


\section{Introduction}

Acceptance and commitment therapy (ACT; Hayes, Luoma, Bond, Masuda, \& Lillis, 2006) is a third wave cognitive behaviour therapy, which proposes that human suffering is raised by psychological inflexibility, that is, the inability to fully and consciously contact the present moment and the incapability to engage in patterns of effective action linked to chosen life values (Hayes, Pistorello, \& Levin, 2012; Hayes, Strosahl, \& Wilson, 1999). ACT's approach to psychopathology highlights the attempt to control or avoid emotions, sensations, memories or thoughts, in ways that are ultimately unsuccessful and actually restrict healthy functioning, as one of the main roots of psychological inflexibility (Hayes et al., 1999, 2006). Under a health-promotion perspective, ACT aims at the development of psychological flexibility, that is, the ability to fully contact the present moment as a conscious human being and persisting or changing behaviour in the service of chosen values (Hayes et al., 1999, 2006).

Psychological flexibility is established through six main interconnected therapeutic processes: acceptance, cognitive defusion, contact with the present moment, self as context, identification of personal life values, and the translation of values into committed action (e.g., Hayes et al., 2006). Rather than aiming at the modification of the frequency, intensity, or content of internal events, this approach seeks to change the function of these events and the relationship that one establishes with one's internal events through the cultivation of all the interrelated therapeutic processes (e.g., Hayes et al., 2006). The promotion of ACT's processes has been shown to constitute a reliable therapeutic approach and to predict long-term adaptive behavioural change (e.g., Hayes, Pistorello, \& Levin, 2012). Specifically, the success of ACT has been proven along several mental health concerns, such as depression (Bohlmeijer, Fledderus, Rokx, \& Pieterse, 2011; Zettle \& Hayes, 1986; Zettle \& Rains, 1989), anxiety disorders (e.g., 
Dalrymple \& Herbert, 2007), and psychological issues associated with physical illnesses, such as oncological conditions (Feros, Lane, Ciarrochi, \& Blackledge, 2013; Low et al., 2016; Mojtabaie \& Gholamhosseini, 2014).

Experiential avoidance is a pathological process of ACT, defined as the effort to control or avoid inner upsetting and/or painful experiences (e.g., Hayes et al., 2012), which is particularly associated to the disruption of committed action (e.g., Hayes et al., 2012). Specifically, when individuals perceive internal experiences as a threat, they often try to escape or avoid them, which ends up increasing the intensity and frequency of such distressing experiences (e.g., Cioffi, \& Holloway, 1993; Koster, Rassin, Crombez, \& Naring, 2003; Hayes et al., 1996). Thus, by creating a focus on the avoidance of events that elicit discomfort, experiential avoidance leads to a restriction in behaviours and activities, which are consistent with personal values (e.g., Hayes, Levin, Plumb-Vilardaga, Villatte, \& Pistorello, 2011). Experiential avoidance is considered as a perpetuator of emotional problems and is linked to depression and distress symptoms in the adult general population (Polusny, Rosenthal, Aban, \& Follette, 2004). This maladaptive emotion regulation process is also associated with decreased mental health in chronic health conditions such as diabetes (e.g., Gregg, Callaghan, Hayes, \& GlennLawson, 2007), chronic pain (e.g., Costa \& Pinto-Gouveia, 2013; Ruiz-Párraga \& López-Martínez, 2015), and breast cancer patients (Aguirre-Camacho et al., 2016).

Committed action is a present-oriented process defined as the enactment of broad patterns of effective actions, which move individuals towards a valued life, that is, behaviours, which are actively chosen and enacted in the service of underlying life values (Hayes et al., 2006, 2012). These behaviours are further characterized as being persistent and flexible, sensitive about the context, and related to the willingness to incorporate pain, discomfort, distress, and failure as a part of the process of pursuing 
one's values (Hayes et al., 1999, 2012; McCracken, 2005, 2013). These life values do not consist of goals (which can be achieved) and are instead regarded as life directions, that is, lifelong ongoing patterns of activity, which are constantly pursued and never fully satisfied (e.g., Hayes et al., 2012). Although committed action has not been investigated to a large extent, specifically in particular populations, several accounts have studied potential positive effects of acting accordingly to chosen values across a variety of mental and physical health indicators, both in non-clinical and clinical populations (McCracken, 2013; McCracken, Chilcot, \& Norton, 2015; Michelson, Lee, Orsillo, \& Roemer, 2011; Trompetter et al., 2013).

In order to increase the effectiveness of ACT approaches to human suffering, the creation of valid measures is crucial, namely, to develop more efficient models and to determine which processes are preponderant to therapeutic change (Kraemer, Wilson, Fairburn \& Agras, 2002; Trompetter et al., 2013). Regarding the process of committed action, the Committed Action Questionnaire (CAQ; McCracken, 2013) was developed within a specific population - a sample of chronic pain patients. The CAQ is the only instrument to exclusively measure the process of committed action (McCracken, 2013) and was proved to be a reliable and valid instrument (high internal consistency of 0.91), with correlations with the concepts of pain acceptance, depression, and general health (McCracken, 2013). Starting as a 18-item instrument, in order to save respondents time and effort and help researchers gather data more efficiently, the CAQ was recently shortened to a version of 8 items (McCracken et al., 2015). Nonetheless, the development of CAQ-18 and CAQ-8 was based in samples of chronic pain patients; therefore, the possibility of generalizing validity findings to other populations requires further investigation (McCracken et al., 2015). 
Taking into account the scarcity of data on the importance of promoting committed action in psychological interventions aimed at reducing human suffering in the general and specific populations and the pertinence of using the CAQ as a committed action-specific measure, this study aimed at studying the psychometric properties of the 8 -item solution of the CAQ in a general adult population sample and also in a specific sample of breast cancer patients (Study 1). Moreover, this paper also aims to analyse the specific role of committed action in the association between experiential avoidance and depressive symptomatology in both studied samples (Study 2).

\section{STUDY 1}

\section{Method}

\section{Participants}

Sample 1: This sample comprises 294 adults from the Portuguese general population (88 males and 206 females), with ages ranging from 18 and 73 years old ( $M$ $=26.88 ; S D=10.66)$. The completed level of education varied between the 4th grade and $\mathrm{PhD}$ (completed years of education: $M=13.70 ; S D=2.21$ ).

Sample 2: This sample includes 82 women with a previous diagnosis of breast cancer, with ages between 28 and 76 years old $(M=50.21 ; S D=9.76)$. In this sample, the completed level of education of the participants ranged from the 9th grade to $\mathrm{PhD}$ (completed years of education: $M=14.10 ; S D=2.37$ ).

\section{Procedure}


Participants from Sample 1 were recruited in Portuguese universities, private companies, and retail services from the Coimbra region, Portugal. The enrolled institutions approved the conduction of the study and its test battery. All the approached individuals were informed about voluntary character of their participation and the confidential nature of the study. After accepting to participate in the study, participants gave their written informed consent and completed the test battery in the presence of one of the authors.

Participants from Sample 2 were recruited through a Portuguese breast cancer support association (Portuguese Association of Support to Women with Breast Cancer; Associação Portuguesa de Apoio à Mulher com Cancro da Mama). The members of these associations registered as patients were invited to participate in the study via an email with information regarding the study's procedures and a link that would redirect the participant to an online survey. Participants were further informed about the voluntary character of their responses and the confidentiality of the data. Participants signed an informed consent before completing self-report measures on an online platform.

\section{Translation of the CAQ-8}

The translation of the CAQ-8 to the Portuguese language from the original English version (Appendix A) was performed in several steps. First, a native speaker of English, also fluent in Portuguese, translated the original items to Portuguese (forward translation; World Health Organization, 2017). The authors of this study (native speakers of Portuguese and fluent in English) translated back the items to English and confirmed the correspondence of each item's content (back translation; Erkut, 2010). After these steps, the translated items were analysed by several individuals from the 
Portuguese general population (monolingual or bilingual) that indicated whether the instructions and the items were clear and easily understandable, and, in the case of the bilingual individuals, whether the items reflected their English versions (pre-testing and interview; Erkut, 2010; World Health Organization, 2017). Taking into account the proposed modifications, the final Portuguese version of the CAQ-8 was then constructed. One of the authors (J. P. G.), an expert on ACT, reviewed the items' content to assure they would adequately represent the measured construct.

\section{Measures}

Participants completed the CAQ-8 and the Portuguese validated versions of the following self-report measures and reported demographic and medical data.

\section{Engaged Living}

Engaged Living Scale (ELS; Trompetter et al., 2013; Portuguese version by Trindade, Ferreira, Pinto-Gouveia, \& Nooren, 2016). The ELS is a process-specific measure designed to assess engaged response style, a concept from ACT defined as the evaluation and enactment of valued life actions. The Portuguese study of the ELS revealed the pertinence of a 9-item structure divided in two subscales: valued living (VL; five items regarding values knowledge and actions congruent with those values) and life fulfilment (LF; four items concerning a "sense of fulfilment in life as a consequence of recognizing and living in accordance with personal values"; Trompetter et al., 2013, p. 5). Items are rated on a 5-point Likert-type scale, ranging between 1 (Completely disagree) and 5 (Completely agree). The ELS showed very good psychometric properties, both in its original study ( $\alpha$ total $=0.90 ; \alpha \mathrm{VL}=0.86 ; \alpha \mathrm{LF}=0.86$ ) and in its Portuguese validation study ( $\alpha$ total $=0.92 ; \alpha \mathrm{VL}=0.88 ; \alpha \mathrm{LF}=0.90$ ).

\section{Experiential Avoidance}


Acceptance and Action Questionnaire (AAQ-II; Bond et al., 2011; Portuguese version by PintoGouveia, Gregório, Dinis, \& Xavier, 2012). This 7-item self-report measure is a reduced version of the original AAQ, designed to measure experiential avoidance (i.e., the attempt to avoid painful internal experiences). Respondents are asked to evaluate the level to each they agree with each statement, using a Likert-type scale rated from 1 (Never true) to 7 (Always true). This scale was found to have satisfactory reliability and validity, with a mean Cronbach's alpha of 0.84 in the original studies and 0.90 in the Portuguese validation study.

\section{Cognitive Fusion}

Cognitive Fusion Questionnaire (CFQ; Gillanders et al., 2014; Portuguese version by PintoGouveia, Dinis, Gregório, \& Pinto, 2011). The CFQ is a brief self-report measure of cognitive fusion, a central concept of the ACT defined as the tendency to be excessively regulated and influenced by cognition and to believe that thoughts are precise reflections of reality. This scale consists of seven items, rated on a Likert-type scale, which ranges from 1 (Never true) to 7 (Always true). The CFQ was shown to be psychometrically sound, with good internal consistencies ( $\alpha=0.92$, both in the original and in the Portuguese validation studies). The CFQ7 was only administered to Sample 1 of this study.

Cognitive Fusion Questionnaire - Chronic Illness (CFQ CI; Trindade, Ferreira, \& PintoGouveia, 2016). This self-report scale is an adaptation of the CFQ (Gillanders et al., 2014; Pinto-Gouveia et al., 2014) and intends to evaluate the process of cognitive fusion associated with a chronic illness and related symptomatology. It comprises seven items measured on a 5point Likert, which ranges from 1 (Never True) to 4 (Always True). The CFQ-CI is a reliable and valid scale, having had presented Cronbach's alpha values of 0.97 and of 0.95 in two samples with different chronic conditions in its validation study. The CFQ-CI was only completed by this study's Sample 2 . 
Shame

Other as Shamer Scale (OAS; Goss et al., 1994; Portuguese version by Matos, Pinto-Gouveia, \& Duarte, 2011). The OAS is an 18-item scale that measures one's level of external shame (i.e., one's perception that others evaluate the self negatively). This scale's items are rated on a 5point scale, ranging from 0 (Never) to 4 (Almost always). In both the original and the Portuguese studies, the scale was showed to be reliable, with $\alpha=0.92$ and $\alpha=0.91$, respectively. In this study, this scale was administered to Sample 1.

Chronic Illness-related Shame Scale (CISS; Trindade, Ferreira, \& Pinto-Gouveia, 2016). This is a unidimensional self-report scale specifically designed to measure shame feelings (internal and external shame) associated with a chronic illness. The CISS is composed of seven items measured on a 5-point Likert scale (from 0 -Never True to 4-Always True). This self-report measure was proved as a robust valid instrument, with Cronbach's alphas between 0.91 and 0.93 in the original study. In this study, only Sample 2 completed the CISS.

\section{Psychopathology}

Depression, Anxiety, and Stress Scales (DASS; Lovibond \& Lovibond, 1995; Portuguese version by Pais-Ribeiro, Honrado, \& Leal, 2004). The DASS is a self-report measure of 21 items, which accesses three negative emotional symptoms through three subscales: depression, anxiety, and stress. Respondents are prompted to use a 4-point scale (ranging from 0-Did not apply to me at all to 3-Applied to me very much, or most of the time) to evaluate the frequency of symptoms in the previous week. The original study, as well as the Portuguese validation, showed that the DASS has good psychometric properties. Specifically, Cronbach's coefficient values for the depression, anxiety, and stress subscales were of $0.94,0.87$, and 0.91 and $0.84,0.80$, and 0.87 , for the original and Portuguese studies, respectively. 


\section{Statistical analyses}

The CAQ-8's structure adequacy was analysed by conducting confirmatory factor analyses (CFAs), with maximum likelihood as the estimation method, using a combined sample $(N=372)$ of Sample $1(n=294)$ and Sample $2(n=82)$. A series of well-known goodness-of-fit indices were selected to analyse the results from the CFAs: the CMIN/df, which should present values inferior to 5 (Hair, Anderson, Tatham, \& Black, 1998), the Comparative Fit Index (CFI) and the Tucker and Lewis Index (TLI), which indicate that the tested model presents a good adjustment to the empirical data when superior than 0.95 (Hu \& Bentler, 1999), and also the Standardized Root Mean Square Residual (SRMS), which is acceptable when inferior to 0.08 (Hu \& Bentler, 1999). The local adjustment of the models was assessed by the standardized regression weights (SRW $[\lambda]$; that should be superior to 0.40; Stevens, 1992) and the standardized multiple correlations (SMC $\left[R^{2}\right]$; that should be superior to 0.20; Hooper, Coughlan, \& Mullen, 2008) of the items.

A multigroup analysis was performed to examine the measurement invariance of the CAQ-8 across the two different samples (Meredith, 1993). When measurement properties are structurally equivalent in different groups, measurement invariance is demonstrated (Meredith, 1993).

Internal reliability analyses of the CAQ- 8 were conducted by examining Cronbach's alpha values, which reveal an acceptable and good internal consistency when superior to 0.60 and 0.70 , respectively (Kline, 2000), for each sample. Composite reliability (which should present values superior to 0.70; Fornell \& Larcker, 1981) was also analysed for Sample 1 and Sample 2. Average variance extraction (which should be superior to 0.50; Fornell \& Larcker, 1981) was calculated and analysed to examine the CAQ-8's convergent validity, also using both samples. The CAQ-8's concurrent and 
divergent validities were examined through the estimation of zero-order correlations between the CAQ-8 and other measures, using a subsample of Sample 1 ( $n=126 ; 90$ females and 36 males) and Sample $2(N=82)$. In addition, partial correlations were performed controlling for ELS, using the same subsample of Sample $1(n=126)$, to test the incremental validity of the CAQ-8.

Pearson correlation coefficients were conducted to analyse CAQ-8's relationships with other measures; these coefficients can have the following effect sizes: small ( $r=0.10$ to 0.29$)$, moderate $(r=0.30$ to 0.49$)$, large $(r=0.50$ to 0.69$)$, very large ( $r=0.70$ to 0.89 ), nearly perfect $(r \geq 0.90)$, and perfect ( $r=1$; Cohen, Cohen, West, \& Aiken, 2003).

IBM SPSS Statistics 20 (IBM Corp, 2011) was used to perform psychometric analyses. The confirmatory factorial structure of the CAQ-8 was analysed with the software AMOS (Arbuckle, 2006).

\section{Results}

\section{Preliminary Analysis}

The analysis of Skewness and Kurtosis' values allowed to conclude that the study variables did not present a significant bias to normal distribution. For Sample 1, Skewness values varied between -0.34 and 2.29 and Kurtosis between -0.44 and 4.17; and for Sample 2, Skewness ranged from 0.40 and 1.39 and Kurtosis from -0.76 to 1.66. Furthermore, the assumption of normality was corroborated by the visual inspection of distributions (Kline, 2000).

\section{Confirmatory Factor Analysis of the CAQ-8}


The structure of CAQ-8 was confirmed through a CFA, using a combined sample of Sample 1 and Sample $2(N=376)$. Given that in the original study by McCracken (2013), only the two-factor and the bi-factor models of the CAQ- 8 were considered acceptable, in this study, only those models will be conducted.

Results regarding the two-factor structure of the CAQ-8 revealed that the model presented a very good fit to the empirical data in both samples: $\mathrm{CMIN} / d f=3.52 ; \mathrm{CFI}=$ 0.96; TLI $=0.95 ;$ SRMS $=0.04$. Furthermore, the local adjustment of the model was also acceptable, with SRWs varying between 0.48 (item 5) and 0.85 (item 4) and SMCs comprised between 0.23 (item 5) and 0.72 (item 4).

Please insert Figure 1 around here

Concerning the results from the bi-factor structure (Figure1), it was shown that the model presented a poor fit to the empirical data: $\mathrm{CMIN} / d f=3.99 ; \mathrm{CFI}=0.94 ; \mathrm{TLI}=$ 0.94; SRMS $=0.06$. Also, results suggested the establishment of a correlation between the error terms of items 5 and 7. Because these items belong to the same factor and portray similar contents, this correlation was established, and the model was reanalysed. The bi-factor model with the error terms of items 5 and 7 correlated was shown to present a good model fit: $\mathrm{CMIN} / d f=3.13 ; \mathrm{CFI}=0.96 ; \mathrm{TLI}=0.96 ; \mathrm{SRMS}=$ 0.06. The local adjustment of the model was also acceptable, with SRWs varying between 0.64 (item 5) and 0.85 (item 2) and SMCs comprised between 0.41 (item 5) and 0.72 (item 2).

The two-factor and the bi-factor models of the CAQ- 8 were thus confirmed to be adequate and robust. 


\section{Multigroup Analysis}

Two multigroup analyses of the two-factor and the bi-factor models modified model were performed to test the measurement invariance of the CAQ-8 across the two different groups (healthy individuals and breast cancer patients).

Results from both models revealed that no differences were found concerning factor weights (two-factor: $X^{2}{ }_{(6)}=11.02 ; p=.088$; bi-factor: $X^{2}{ }_{(1)}=0.364 ; p=.546$ ), which indicates structural model invariance between the two samples in study.

\section{Reliability and validity}

Regarding the healthy participants (Sample 1), the CAQ-8 presented an overall good internal consistency, with Cronbach's alphas of 0.86 (total scale), 0.87 (positive subscale), and 0.76 (negative subscale). Furthermore, concerning breast cancer patients (Sample 2), the CAQ-8 presented Cronbach's alphas of 0.79 (total scale), 0.88 (positive subscale), and 0.66 (negative subscale).

Composite reliability's values were 0.91 (Sample 1) and 0.91 (Sample 2), indicating that the scale has construct reliability. Average variance extraction presented values of 0.56 (Sample 1) and 0.55 (Sample 2), indicating that the CFQ-CI presents convergent validity.

\section{Concurrent, divergent and incremental validity}

As shown in Table 1 , in a subsample of Sample $1(n=126)$, the CAQ-8 presented positive and large associations with the measure of engaged living (ELS) and its VL subscale. ELS's LF subscale correlated negatively and moderately with CAQ-8. Furthermore, the CAQ-8 presented positive and large correlations with psychological 
inflexibility (AAQ-II), general cognitive fusion (CFQ-7), and depressive symptomatology (DASS-21). The CAQ-8 was also positively and moderately linked to shame (OAS), anxiety (DASS-21), and stress (DASS-21). Results from the partial correlations controlling for the ELS revealed that the CAQ-8's correlations with the other measures remained significant (Table 1), which supports CAQ-8's incremental validity.

Regarding Sample $2(N=82)$, results (Table 2) showed that the CAQ-8 presented negative and moderate associations with psychological inflexibility (AAQ-II), chronic illness-related cognitive fusion (CFQ-CI), chronic illness-related shame (CISS), anxiety, and stress (DASS-21). The relationship between CAQ-8 and depressive symptomatology (DASS-21) was positive and large.

Please insert Tables 1 and 2 around here

\section{STUDY 2}

\section{Aims and method}

To explore the mediator effect of committed action (CAQ-8) on the relationship between experiential avoidance (AAQ-II) and depressive symptomatology (DASS-21) in both groups (healthy individuals and breast cancer patients), a second study was conducted.

Pearson correlations were performed to explore the relationship between variables, and a path analysis was conducted to test a theoretical model that analysed the hypothesized meditational role of committed action. This analysis was conducted using AMOS software (Arbuckle, 2006), with maximum likelihood as estimation method. Path analysis is a type of structural equation modelling that examines structural 
relationships and direct and indirect paths (Schumacker \& Lomax, 2004). The bootstrap procedure (with 5,000 samples) was used to create $95 \%$ bias-corrected confidence intervals (CIs) around the standardized estimates of total, direct, and indirect effects. If the interval between the lower and the upper bound of the $95 \%$ bias-corrected CI does not include zero, the effects are considered statistically significant (Kline, 2005). The goodness-of-fit indices used in Study 1 were also used in Study 2 to examine the model's fit to the empirical data.

The sample $(N=208)$ used in Study 2 was the combination of the subsample of Sample $1(n=126)$ and the total of Sample $2(N=82)$.

\section{Results}

\section{Correlations}

Results from the correlation analyses (Table 3) demonstrated that committed action presented negative and large associations with experiential avoidance and depressive symptomatology. Furthermore, these two variables were strongly and positively correlated with each other.

Please insert Tables 3 around here

The impact of committed action on the association between experiential avoidance and depression symptoms

The tested theoretical model (Figure 2) explored whether the engagement in committed action would significantly mediate the effect of experiential avoidance on depressive symptomatology in a combined sample of healthy participants and breast 
cancer patients $(N=208)$. This model presented 11 parameters and explained $29 \%$ of committed action and $41 \%$ of depression symptoms. Furthermore, all individual path coefficients were statistically significant, and the model was saturated.

Experiential avoidance presented a direct effect of -0.54 on committed action $\left(b_{\mathrm{AAQ}-\mathrm{II}}=-0.41 ; S E=0.04 ; Z=-9.23 ; p<.001 ; 95 \% \mathrm{CI}[-0.63,-0.44] ; p<.001\right)$ and $\mathrm{a}$ direct effect of 0.46 on depressive symptomatology $\left(b_{\mathrm{AAQ}-\mathrm{II}}=0.21 ; S E=0.03 ; Z=7.18\right.$; $p<.001 ; 95 \%$ CI $[0.31,0.59] ; p<.001)$. Depressive symptomatology was also significantly predicted by committed action with a direct effect of $-0.27\left(b_{\mathrm{CAQ}-8}=\right.$ $-0.16 ; S E=0.04 ; Z=-4.18 ; p<.001 ; 95 \%$ CI $[-0.41,-0.12] ; p<.001)$. Results also revealed that experiential avoidance presented an indicted effect of 0.14 on depression symptoms through the mechanisms of committed action $(95 \%$ CI $[-0.03$ to 0.14$] ; p<$ $.001)$

A multigroup analysis was conducted to test the measurement invariance of the model across the two different groups (healthy individuals and breast cancer patients). No differences were found regarding factor weights $\left(X^{2}{ }_{(3)}=5.44 ; p=.143\right)$, which establishes model invariance between the two groups.

Please insert Figure 2 around here

\section{Discussion}

The first study of this paper aimed to validate the psychometric properties of the CAQ-8 (that had been only validated for the chronic pain population) using two samples: a sample of healthy individuals of both genders and a sample of female breast cancer patients. For both samples, the CAQ-8 was revealed to be a robust 8 -item scale with two subscales (a positive and a negative one). Overall, the scale presented internal 
consistency (although the negative subscale presented a barely acceptable Cronbach's alpha, which may limit the use of this subscale in the Portuguese population) and good construct, convergent, concurrent, and divergent validity. Further, the CAQ-8 presented incremental validity over a measure of engaged living. Our findings also demonstrated measurement invariance between healthy individuals and breast cancer patients for both the two-factor and bi-factor CFA models. Results thus suggest that the total, positive, and negative subscales are adequate for use in the studied populations. Along these lines, this study expands the utility of the CAQ-8 by enabling its use in healthy and cancer populations.

This study corroborates previous findings (McCracken et al., 2015; Trompetter et al., 2013) showing that committed action presents important links with other facets of psychological flexibility and relevant negative associations with psychopathology (namely, depression and anxiety symptoms). Nevertheless, this paper adds to literature by being, to our current knowledge, the first investigation to particularly study committed action in a cancer population.

This study also expands previous literature by examining committed action's individual effect in the well-established relationship between experiential avoidance and depression symptoms. This meditational model, which was shown to be invariant between the two analysed groups (healthy participants and breast cancer patients), demonstrates that part of the effect that experiential avoidance holds on depressive symptomatology is explained by the mechanisms of committed action. This seems to support that the engagement in experiential avoidance (by attempting to control or avoid thoughts, emotions, or physical sensations) may lead to behavioural patterns (which might include behavioural avoidance of activities that may potentially be associated with emotional or physical discomfort), which in turn was shown to predict depressive 
symptomatology. The link between committed action and depression symptoms can be explained by the possible avoidance of activities that are valued and important to the individual and to some level of related avoidance of leisure, mastery, and social activities. Still, experiential avoidance seems to present an individual, direct effect on depressed mood, probably due to its documented paradoxical effects (e.g., Cioffi, \& Holloway, 1993; Koster et al., 2003; Hayes et al., 1996). This result thus corroborates extensive literature regarding the detrimental effects of experiential avoidance on mental health (Aguirre-Camacho et al., 2016; Costa \& Pinto-Gouveia, 2013; Gregg et al., 2007; Polusny et al., 2004; Ruiz-Párraga\& López-Martínez, 2015).

It is important to highlight that these mechanisms seem to hold similar effects on healthy people and cancer patients. It can thus be emphasized that the studied processes are universal and that humans seem to recur to these types of emotion regulation when facing or not the adversities of a disease such as cancer and that the use of these processes presents similar effects on mental health in both cases. Therefore, psychotherapeutic interventions may benefit from including components of acceptance, values clarification, and committed action to target mental health issues, in both cancer and non-cancer populations.

These findings should be considered taking into consideration several limitations. First, it is important to note that our results may not be generalized due to our samples' features. Future studies should replicate the findings of this paper in larger samples and in other populations and cultures. Further, given that the form of administration of the test battery to the cancer sample was made through an online platform, this sample may be biased because it only comprises patients who have internet access and ability to fill an online survey. Future studies should address this issue by recruiting patients from medical centres. Furthermore, due to the cross- 
sectional nature of this study, committed action's relationships with the other studied measures should not be considered causal. Future research ought to conduct longitudinal designs exploring committed action's link with health and mental functioning and test CAQ-8's sensitivity to change in programme interventions targeting committed action. Finally, regarding the tested meditational model, we acknowledge that other emotion regulation processes (e.g., cognitive fusion and decentering) may be involved in the studied associations and that therefore the model should be further explored in future research.

Overall, this study showed that the CAQ-8 is a reliable instrument that may be used in healthy and cancer populations. This instrument presents the advantage of specifically and particularly assessing committed action, a facet of psychological flexibility little studied to date but, nevertheless, as this study demonstrates, strongly linked with important mental health outcomes.

\section{Funding}

Research by the first author (Inês A. Trindade) is supported by a Ph.D. Grant (SFRH/BD/101906/2014) sponsored by FCT (Portuguese Foundation for Science and Technology).

\section{Acknowledgements}

We are thankful for the help given by the Portuguese Association of Support to Women with Breast Cancer (Associação Portuguesa de Apoio à Mulher com Cancro da Mama) during the recruitment process of the present research. 


\section{References}

Aguirre-Camacho, A., Pelletier, G., González-Márquez, A., Blanco-Donoso, L. M., García-a-Borreguero, P., \& Moreno-Jiménez, B. (2016). The relevance of experiential avoidance in breast cancer distress: Insights from a psychological group intervention. Psycho-Oncology. https://doi.org/10.1002/pon.4162

Arbuckle, J. L. (2006). Amos (version 7.0) [computer program]. Chicago: SPSS.

Bohlmeijer, E. T., Fledderus, M., Rokx, T. A., \& Pieterse, M. E. (2011). Efficacy of an early intervention based on acceptance and commitment therapy for adults with depressive symptomatology: Evaluation in a randomized controlled trial. Behaviour Research and Therapy, 1, 62-67. https://doi.org/10.1016/j.brat.2010.10.003

Bond, F. W., Hayes, S. C., Baer, R. A., Carpenter, K. C., Guenole, N., Orcutt, H. K., ... Zettle, R. D. (2011). Preliminary psychometric properties of the Acceptance and Action Questionnaire - II: A revised measure of psychological flexibility and acceptance. Behavior Therapy, 676-688. https://doi.org/10.1016/j.beth.2011.03.007

Cioffi, D., \& Holloway, J. (1993). Delayed costs of suppressed pain. Journal of Personality and Social Psychology, 64, 274-282.

Cohen, J., Cohen, P. West, S., \& Aiken, L. (2003.) Applied multiple regression/correlation analysis for the behavioral sciences (3th ed.). New Jersey: Lawrence Erlbaum Associates.

Costa, J., \& Pinto-Gouveia, J. (2013). Experiential avoidance and self-compassion in chronic pain. Journal of Applied Social Psychology, 43(8), 1578-1591. https://doi.org/10.1111/jasp.12107 
Dalrymple, K. L., \& Herbert, J. D. (2007). Acceptance and commitment therapy for generalized social anxiety disorder: A pilot study. Behavior Modification, 31(5), 543-568. https://doi.org/10.1177/0145445507302037

Erkut, S. (2010). Developing multiple language versions of instruments for intercultural research. Child Development Perspectives, 4, 19-24. https://doi.org/10.1111/j.1750-8606.2009.00111.x

Feros, D. L., Lane, L., Ciarrochi, J., \& Blackledge, J. T. (2013). Acceptance and commitment therapy (ACT) for improving the lives of cancer patients: A preliminary study. Psychooncology, 22(2), 459-464. https://doi.org/10.1002/pon.2083

Fornell, C., \& Larcker, D. F. (1981). Evaluating structural equation models with unobservable variables and measurement error. Journal of Marketing Research, 18, 39-50. https://doi.org/10.2307/3151312

Gillanders, D. T., Bolderston, H., Bond, F. W., Dempster, M., Flaxman, P. E., Campbell, L., ... Remington, R. (2014). The development and initial validation of the Cognitive Fusion Questionnaire. Behavior Therapy, 45, 83-101. https://doi.org/10.1016/j.beth.2013.09.001

Goss, K., Gilbert, P., \& Allan, S. (1994). An exploration of shame measures: The Other as Shamer Scale. Personality and Individual Differences, 17(5), 713-717. https://doi.org/10.1016/0191-8869(94)90149-X

Gregg, J. A., Callaghan, G. M., Hayes, S. C., \& Glenn-Lawson, J. L. (2007). Improving diabetes self-management through acceptance, mindfulness, and values: A randomized controlled trial. Journal of Consulting and Clinical Psychology, 75, 336-343. https://doi.org/10.1037/0022-006X.75.2.336 
Hair, J. F., Anderson, R. E., Tatham, R. L., \& Black, W. C. (1998). Multivariate Data Analysis. Prentice-Hall International.

Hayes, S. C., Levin, M. E., Plumb-Vilardaga, J., Villatte, J. L., \& Pistorello, J. (2011). Acceptance and commitment therapy and contextual behavioral science: Examining the progress of a distinctive model of behavioral and cognitive therapy. Behavior $\quad$ Therapy, $\quad 2, \quad 180-198$. https://doi.org/10.1016/j.beth.2009.08.002

Hayes, S. C., Luoma, J. B., Bond, F. W., Masuda, A., \& Lillis, J. (2006). Acceptance and commitment therapy: Model, processes and outcomes. Behaviour Research and Therapy, 1, 1-25. https://doi.org/10.1016/j.brat.2005.06.006

Hayes, S. C., Pistorello, J., \& Levin, M. E. (2012). Acceptance and commitment therapy as a unified model of behavior change. The Counseling Psychologist, 40(7), 976-1002. https://doi.org/10.1177/0011000012460836

Hayes, S. C., Strosahl, K., \& Wilson, K. G. (1999). Acceptance and commitment therapy: An experiential approach to behavior change. New York: The Guilford Press.

Hayes, S. C., Wilson, K. G., Gifford, E. V., Follette, V. M., \& Strosahl, K. (1996). Experiential avoidance and behavioral disorders: A functional dimensional approach to diagnosis and treatment. Journal of Consulting and Clinical Psychology, 64, 1152-1168.

Hooper, D., Coughlan, J., \& Mullen, M. R. (2008). Structural equation modelling: Guidelines for determining model fit. The Electronic Journal of Business Research Methods, 6(1), 53-60.

Hu, L., \& Bentler, P. M. (1999). Cutoff criteria for fit indexes in covariance structure analysis: Conventional criteria versus new alternatives. Structural Equation 
Modeling: $\quad$ A $\quad$ Multidisciplinary Journal, $\quad 6(1), \quad 1-55$. https://doi.org/10.1080/10705519909540118

IBM Corp. Released (2011). IBM SPSS statistics for windows, Version 20.0. Armonk, NY: IBM Corp.

Kline, P. (2000). The handbook of psychological testing (2nd ed.). (pp. 13). London: Routledge.

Kline, R. B. (2005). Principles and practice of structural equation modeling. New York: The Guilford Press.

Koster, E. H., Rassin, E., Crombez, G., \& Näring, G. W. (2003). The paradoxical effects of suppressing anxious thoughts during imminent threat. Behaviour Research and Therapy, 9, 1113-1120.

Kraemer, H. C., Wilson, G. T., Fairburn, C. G., \& Agras, W. S. (2002). Mediators and moderators of treatment effects in randomized clinical trials. Archives of General Psychiatry, $\quad$ 59(10), 877-883. https://doi.org/10.1001/archpsyc.59.10.877

Lovibond, P. F., \& Lovibond, S. H. (1995). The structure of negative emotional states: Comparison of the Depression Anxiety Stress Scales (DASS) with the Beck Depression and Anxiety Inventories. Behaviour Research and Therapy, 33(3), 335-343. https://doi.org/10.1016/0005-7967(94)00075-U

Low, J., Serfaty, M., Davis, S., Vickerstaff, V., Gola, A., Omar, R. Z., ... Jones, L. (2016). Acceptance and commitment therapy for adults with advanced cancer (CanACT): Study protocol for a feasibility randomised controlled trial. Trials, 17(77). https://doi.org/10.1186/s13063-016-1169-8

Matos, M., Pinto-Gouveia, J., \& Duarte, C. (2011). Other as Shamer. Versão portuguesa e propriedades psicométricas de uma medida de vergonha externa 
[Other as Shamer: Portuguese version and psychometric properties of a measure of external shame]. Submitted manuscript.

McCracken, L. M. (2005). Contextual cognitive-behavioral therapy for chronic pain. Seattle, WA: International Association for the Study of Pain.

McCracken, L. M. (2013). Committed action: An application of the psychological flexibility model to activity patterns in chronic pain. The Journal of Pain: Official Journal of the American Pain Society, 8, 828-835. https://doi.org/10.1016/j.jpain.2013.02.009

McCracken, L. M., Chilcot, J., \& Norton, S. (2015). Further development in the assessment of psychological flexibility: A shortened Committed Action Questionnaire (CAQ-8). European Journal of Pain, 19(5), 677-685. https://doi.org/10.1002/ejp.589

Meredith, W. (1993). Measurement invariance, factor analysis and factorial invariance. Psychometrika, 58(4), 525-543. https://doi.org/10.1007/BF02294825

Michelson, S. E., Lee, J. K., Orsillo, S. M., \& Roemer, L. (2011). The role of valuesconsistent behavior in generalized anxiety disorder. Depression and Anxiety, 28(5), 358-366. https://doi.org/10.1002/da.20793

Mojtabaie, M., \& Gholamhosseini, S. (2014). Effectiveness of acceptance and commitment therapy (ACT) to reduce the symptoms of anxiety in women with breast cancer. Journal of Social Issues \& Humanities, 4(2), 522-527.

Pais-Ribeiro, J. L., Honrado, A., \& Leal, I. (2004). Contribuição para o estudo da adaptação Portuguesa das Escalas de Ansiedade, Depressão e Stress (EADS-21) [Contribution to the Portuguese adaptation of the Depression, Anxiety and Stress scales (DASS-21)]. Psychologica, 36, 235-246. 
Pinto-Gouveia, J., Dinis, A., Gregório S. \& Pinto, A. (2014). The preliminary psychometric properties of the Portuguese version of the Cognitive Fusion Questionnaire. Manuscript in preparation.

Pinto-Gouveia, J., Gregório, S., Dinis, A., \& Xavier, A. (2012). Experiential avoidance in clinical and non-clinical samples: AAQ-II Portuguese version. International Journal of Psychology \& Psychological Therapy, 12(2), 139-156.

Polusny, M. A., Rosenthal,M. Z., Aban, I., \& Follette, V. M. (2004). Experimental avoidance as a mediator of the effects of adolescent sexual victimization on negative adult outcomes. Violence and Victims, 1, 109-120.

Ruiz-Párraga, G. T., \& López-Martínez, A. E. (2015). The role of experiential avoidance, resilience and pain acceptance in the adjustment of chronic back pain patients who have experienced a traumatic event: A path analysis. Annals of Behavioral Medicine, 49(2), 247-257. https://doi.org/10.1007/s12160-014-96543

Schumacker, R. E., \& Lomax, R. G. (2004). A beginner's guide to structural equation modeling (2nd ed.). Mahwah, NJ: Lawrence Erlbaum Associates.

Stevens, J. P. (1992). Applied multivariate statistics for the social sciences (2nd ed.). Hillsdale: Erlbaum.

Trindade, I. A., Ferreira, C., \& Pinto-Gouveia, J. (2016a). Assessment of chronic illnessrelated cognitive fusion: Development and validation of a new scale. Submitted manuscript.

Trindade, I. A., Ferreira, C., \& Pinto-Gouveia, J. (2016b). Chronic illness-related shame: Development of a new scale and novel approach for IBD patients' depressive symptomatology. Clinical Psychology \& Psychotherapy. https://doi.org/10.1002/cpp.2035 
Trindade, I. A., Ferreira, C., Pinto-Gouveia, J., \& Nooren, L. (2016). Clarity of personal values and committed action: Development of a shorter engaged living scale. Journal of Psychopathology and Behavioral Assessment, 38(2), 258-265. https://doi.org/10.1007/s10862-015-9509-7

Trompetter, H. R., Ten Klooster, P. M., Schreurs, K. M., Fledderus, M., Westerhof, G. J., \& Bohlmeijer, E. T. (2013). Measuring values and committed action with the engaged living scale (ELS): Psychometric evaluation in a nonclinical sample and a chronic pain sample. Psychological Assessment, 4, 1235-1246. https://doi.org/10.1037/a0033813

World Health Organization. Process of translation and adaptation of instruments. n.d. $\begin{array}{llll}\text { Retrieved } \quad \text { January } & 16, & \text { forl, }\end{array}$ http://www.who.int/substance_abuse/research_tools/translation/en/index.html

Zettle, R. D., \& Hayes, S. C. (1986). Dysfunctional control by client verbal behavior: The context of reason giving. The Analysis of Verbal Behavior, 4, 30-38.

Zettle, R. D., \& Rains, J. C. (1989). Group cognitive and contextual therapies in treatment of depression. Journal of Clinical Psychology, 3, 436-445. 


\section{Table 1}

Zero-Order and Partial Correlations between the CAQ-8 and other measures, and their respective Cronbach's Alphas (Subsample of Sample 1; $n=126$ ).

\begin{tabular}{lccc}
\hline & & & CAQ-8 \\
Measures & $\alpha$ & Zero-order & Partial correlation \\
& & correlation & (controlling for \\
& & & ELS) \\
ELS-9 & 0.87 & $0.60^{* * *}$ & - \\
ELS-VL & 0.80 & $0.59 * * *$ & - \\
ELS-LF & 0.87 & $0.48^{* * *}$ & - \\
AAQ-II & 0.93 & $-0.64 * * *$ & $-0.49 * * *$ \\
CFQ-7 & 0.96 & $-0.66^{* * * *}$ & $-0.54 * * *$ \\
OAS & 0.94 & $-0.47 * * *$ & $-0.28 * * *$ \\
DEP & 0.90 & $-0.51^{* * * *}$ & $-0.33^{* * * *}$ \\
ANX & 0.87 & $-0.40^{* * * *}$ & $-0.23 *$ \\
\hline STR & 0.91 & $-0.46^{* * * *}$ & $-0.33^{* * * *}$ \\
\hline
\end{tabular}

Note. CAQ-8 = Committed Action Questionnaire; ELS-9 = Engaged Living Scale (total score); ELS-VL $=$ Valued Living subscale of the Engaged Living Scale; ELS-LF $=$ Life Fulfilment subscale of the Engaged Living Scale; AAQ-II = Acceptance and Action Questionnaire; CFQ-7 = Cognitive Fusion Questionnaire; OAS = Other as Shamer Scale; DEP, ANX, STR = subscales of the Depression, Anxiety and Stress subscales.

$* p<0.05 ; * * p<0.01 ; * * * p<0.001$ 


\section{Table 2}

Zero-Order correlations between the CAQ-8 and other measures, and their respective Cronbach's Alphas (Sample 2; $N=82$ ).

\begin{tabular}{ccccccc}
\hline & AAQ-II & CFQ-CI & CISS & DEP & ANX & STR \\
\hline$\alpha$ & 0.95 & 0.95 & 0.86 & 0.92 & 0.86 & 0.91 \\
CAQ-8 & $-0.45^{* * *}$ & $-0.45^{* * *}$ & $-0.36^{* *}$ & $-0.53 * * *$ & $-0.48^{* * * *}$ & $-0.46^{* * *}$ \\
\hline
\end{tabular}

Note. CAQ-8 = Committed Action Questionnaire; CFQ-CI = Cognitive Fusion Questionnaire - Chronic Illness; CISS $=$ Chronic Illness Shame Scale; DEP, ANX, STR = subscales of the Depression, Anxiety and Stress subscales.

$* * p<0.01 ; * * * p<0.001$ 


\section{Table 3}

Means (M), Standard Deviations (SD), and intercorrelation scores of the study variables $(N=$ 208)

\begin{tabular}{lccccc}
\hline & $M$ & $S D$ & CAQ-8 & AAQ-II & DEP \\
\hline CAQ-8 & 32.98 & 7.27 & 1 & & \\
AAQ-II & 20.09 & 9.67 & $-0.54 * * *$ & 1 & \\
DEP & 3.58 & 4.40 & $-.051 * * *$ & $0.60 * * *$ & 1 \\
\hline
\end{tabular}

Note. CAQ-8 = Committed Action Questionnaire; AAQ-II = Acceptance and Action Questionnaire; DEP = Depression subscale of the Depression, Anxiety and Stress Scales-21.

$* * * p<0.001$ 
Figure 1

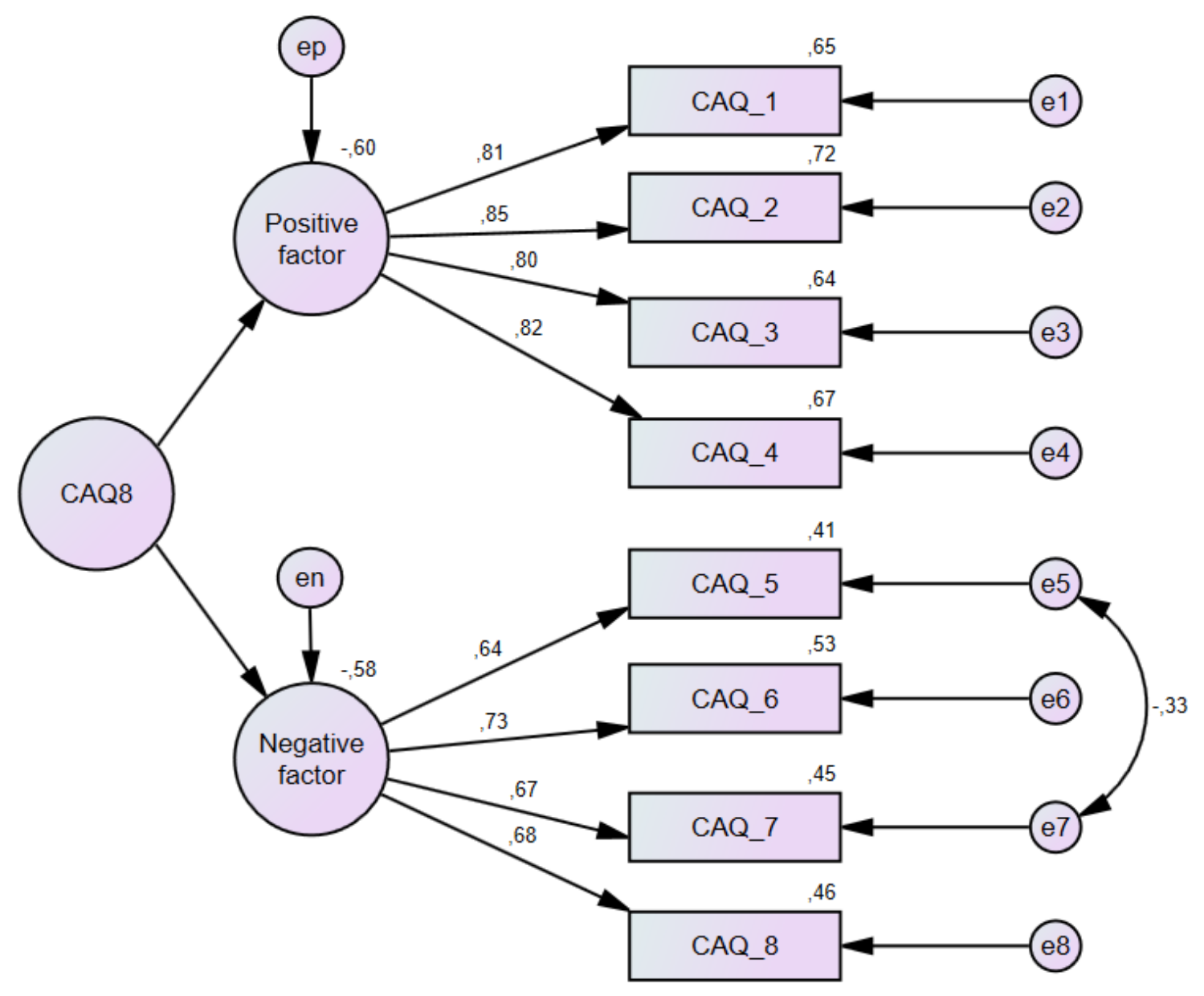

Bi-factor model of the CAQ-8 $(N=376)$ 


\section{Figure 2}

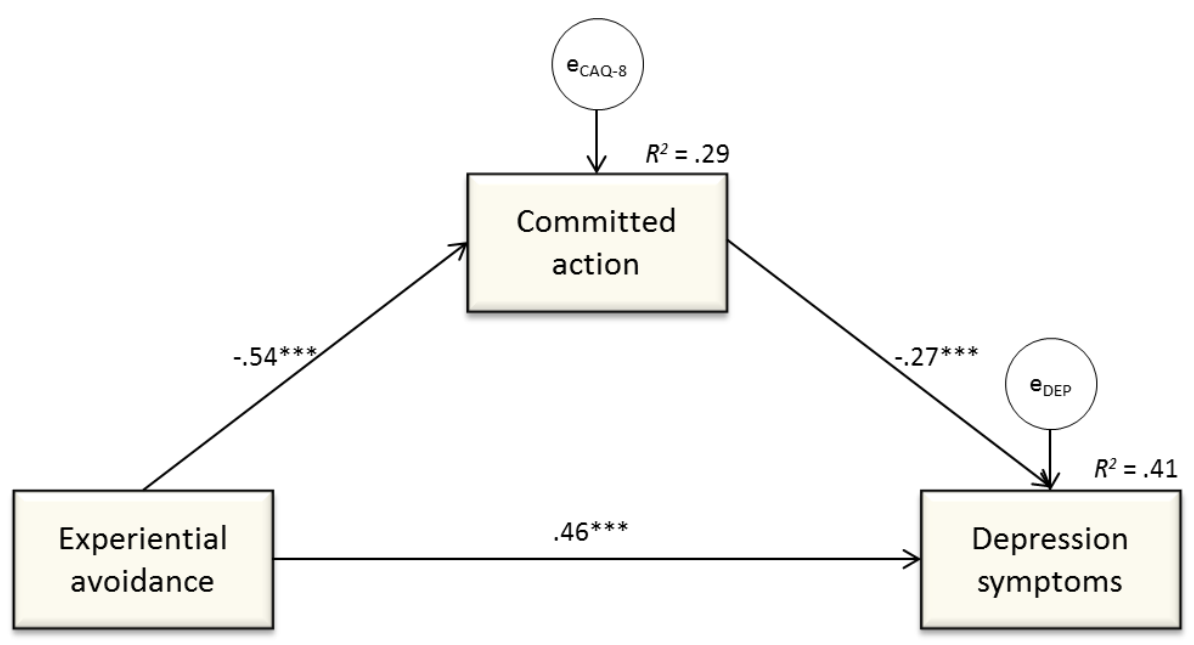

Note. CAQ-8 = Committed Action Questionnaire; DEP $=$ Depression subscale of the Depression, Anxiety and Stress Scales-21.

$* * * p<0.001$ 


\section{Appendix}

Items of the CAQ-8 (English version; McCracken, Chilcot, \& Norton, 2015)

1 I can remain committed to my goals even when there are times that I fail to reach them

2 When a goal is difficult to reach, I am able to take small steps to reach it

3 I prefer to change how I approach a goal rather than quit

4 I am able to follow my long terms plans including times when progress is slow

5 I find it difficult to carry on with an activity unless I experience that it is successful $(r)$

6 If I feel distressed or discouraged, I let my commitments slide $(r)$

7 I get so wrapped up in what I am thinking or feeling that I cannot do the things that matter to me $(r)$

8 If I cannot do something my way, I will not do it at all $(r)$ 